\title{
Building an 8 Cable Elevator System
}

\author{
Mark Louis Gartzman \\ Evanston, Illinois
}

\begin{abstract}
Bachelor of Arts and Sciences; Theatre Production and Design Illinois State University, 2011
\end{abstract}

A Thesis presented to the Graduate Faculty

\begin{abstract}
of the University of Virginia in Candidacy for the Degree of
\end{abstract} Master of Fine Arts

Department of Drama

University of Virginia

May, 2014 
Stage elevators, or lifts, have been used continuously in entertainment for nearly two millennia. Their use dates back as far as 80 A.D., when man-powered winch lifts were used in the Roman Coliseum. Over time, stage elevators evolved from the manpowered winch system of the Roman Empire to the advanced technology used in current productions. Today's technology elevates musicians, actors, magicians, and other performers to stage level with unprecedented ease.

Presently, stage lifts are used in a variety of settings, from large-scale productions to small community theatres. There are many ways to build a stage elevator using a variety of materials, depending on the need for the show, your budget, and the skill level of your shop.

There are a variety of types of stage elevators and lifts, Gala, hydraulic, scissor, screw cable and pneumatic. There are two types that are regularly used for on-stage elevator effects: pneumatic and cable driven. A pneumatic system uses pneumatic, or airpowered, piston cylinders to push the carriage up and pull it down. Pneumatic elevators are great for theatres with little or no room underneath the stage for the elevator to sit, since they do not require rigging points and are often compact. Another highly used type of elevator is a cable system. A cable system uses multiple cables to raise and lower the carriage along a set of rails. The rails are meant to stabilize the carriage as well as guide it through the elevator's trap opening. Sheaves, or stationary pulleys, are required to guide the cables through their set path and turn the cabling in any desired direction, preventing the cables from bending past the required fleet angle. A fleet angle is the angle between the centerline through a sheave and the centerline of the wire rope leading to a second sheave. Bending a cable past its fleet angle lowers the lifts load capacity by 
putting uneven stress on the cable and on the sheave. It also causes rubbing or cutting into your sheave, which can reduce the life of the cable and sheave or cause the cable to come off the sheave. In either of these instances, the carriage can either tip or cause a free fall of the carriage and/or performer riding it. The cables can either run through the sheaves to a clew (a tool that combines multiple cables into a single one to allow one cable to be fed into the drum (Figure 1)) or straight into its power source, also known as a winch drum (Figure 2). The power source does not need to be a drum winch, it can be done as easy as using a counter weight.

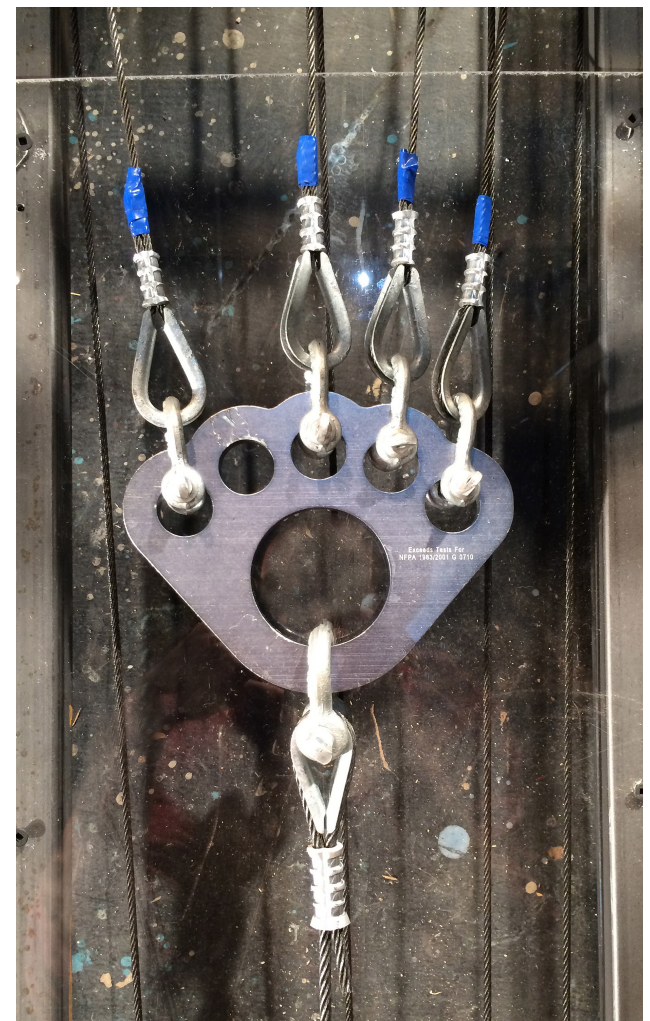

Figure 1. A Clew

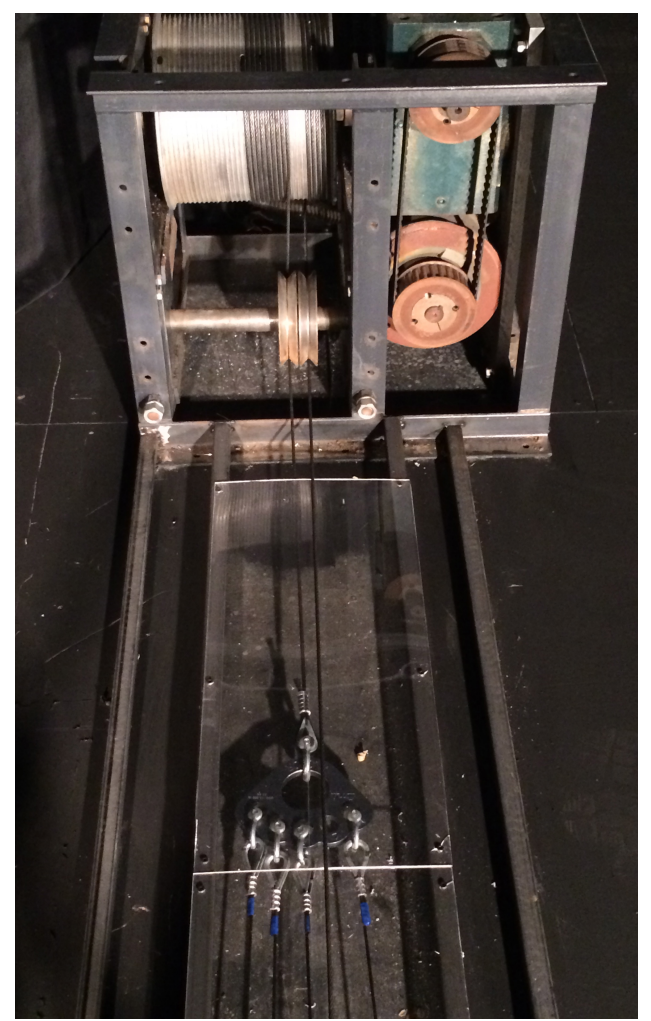

Figure 2. The single cables sent into the drum 
For my thesis, I built a 5-foot tall mock up of an eight-cable elevator system with a freestanding elevator tower. I chose to build an 8 cable system because after a great deal of research I believe this a completely comprehensive, extremely safe and fairly inexpensive way to build a stage elevator. A freestanding tower (Figure 3) ensures that each leg of the track is level and square because they can be built in a shop with jigs to ensure precision (Figure 4).

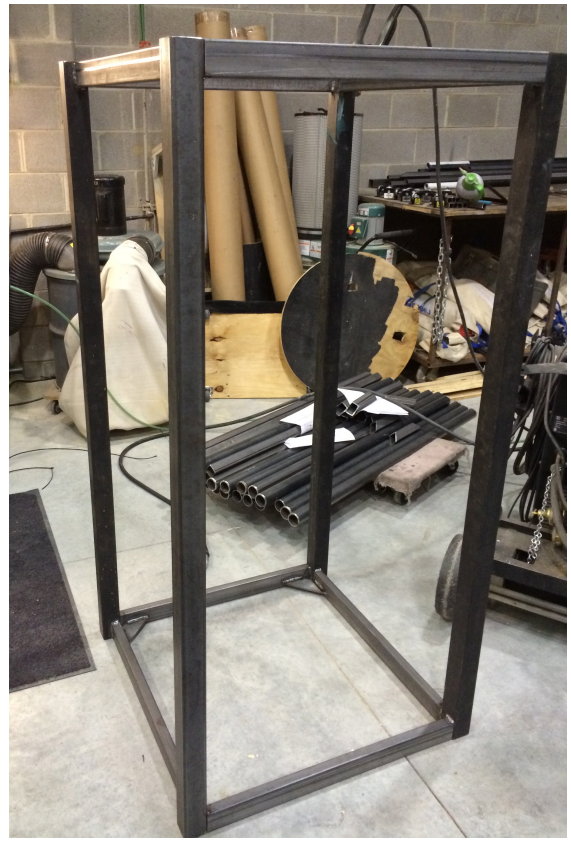

Figure 3. Finished Elevator tower Frame

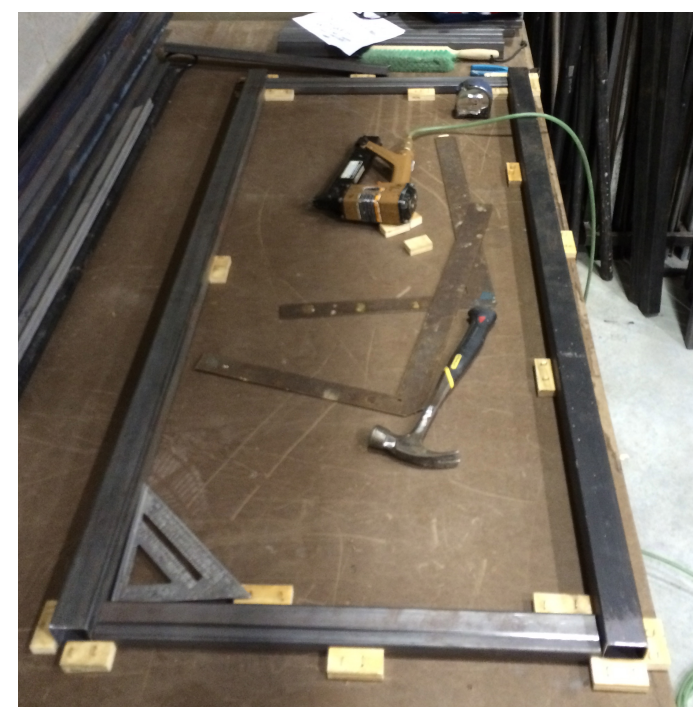

Figure 4. The completed tower jig.

The freestanding tower also provides a self-contained area for all of the rigging (Figure 5). This means that all of the rigging is attached straight to the tower instead of relying on the structure of the theatre to attach your rigging. Everything needed to run the elevator, besides the power source, already exists as part of the unit. Building a freestanding lift creates a stock piece that can easily move to any trap opening under the stage. A stock piece is a scenic unit that is saved in storage and can be used in a variety of shows and settings. 


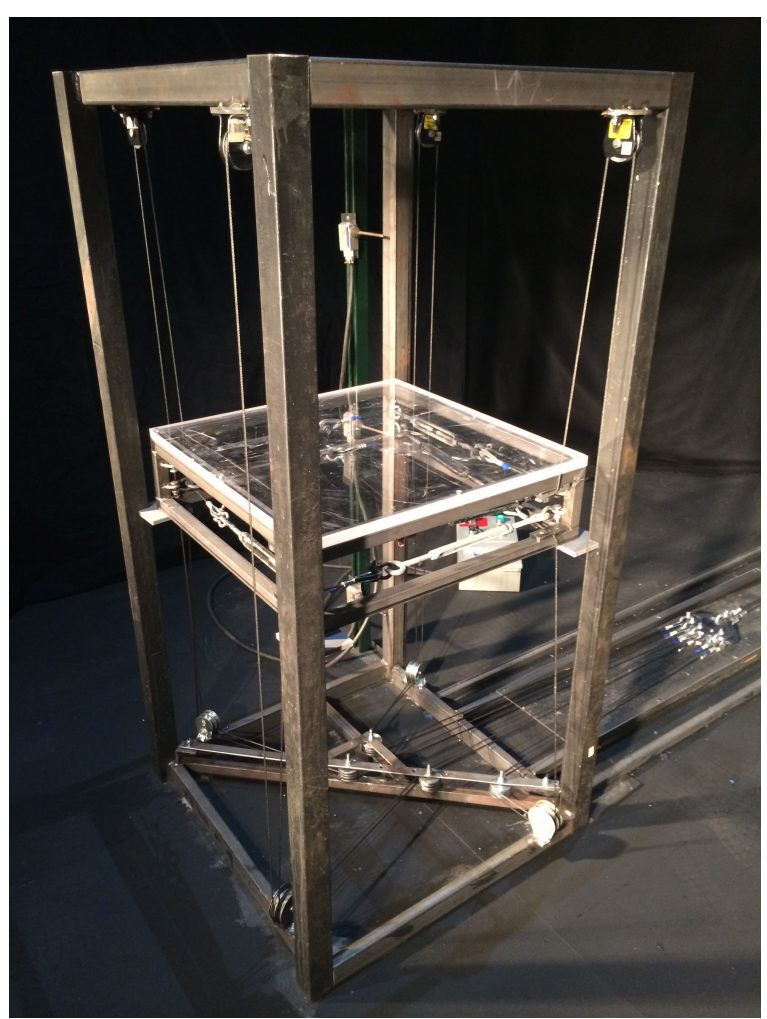

Figure 5. Self Contained Rigging

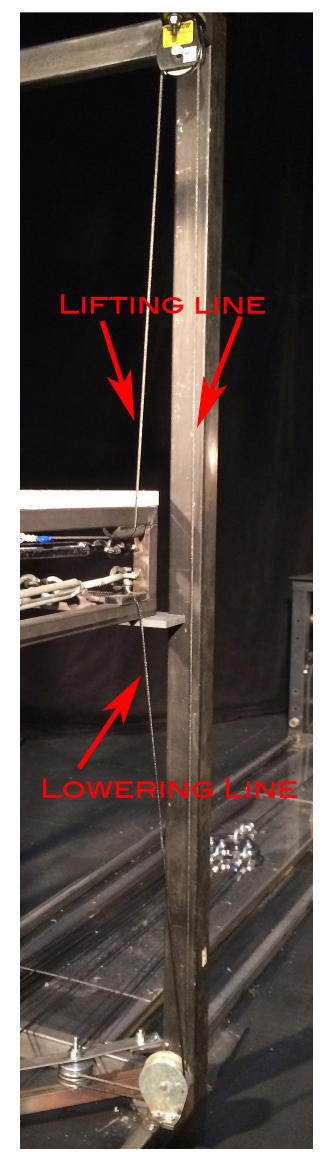

Figure 6. Lifting and Lowering Cables

An eight-cable system consists of four lifting cables and four lowering cables

(Figure 6). Including both lifting and lowering cables reduces friction between the legs and the carriage by constantly having tension on the carriage. It also prevents the carriage from getting stuck on the rails while it moves along the track. If a carriage becomes stuck, it could result in a cable snapping or a jump in the carriage. If the carriage becomes stuck and jumps, this could cause a shock load, which can reduce the lifting capacity of the cables.

Having an 8 cable system with lifting and lowering lines also gives you the opportunity to build a lightweight carriage. A cable system with only lifting cables requires the carriages must be heavy enough to lower itself along the track. Each of the 
four corners of the freestanding tower include a lifting and a lowering cable. A sheave was placed in line with each of the cables. A single sheave also called a loft block, was placed on the top of the tower for the lifting cable to run through, while a double sheave, or head block, was installed on the bottom for both the lifting and lowering cables to run through. To allow for easy leveling of the carriage, turnbuckles were added to each cable inside the carriage (Figures 7,8).

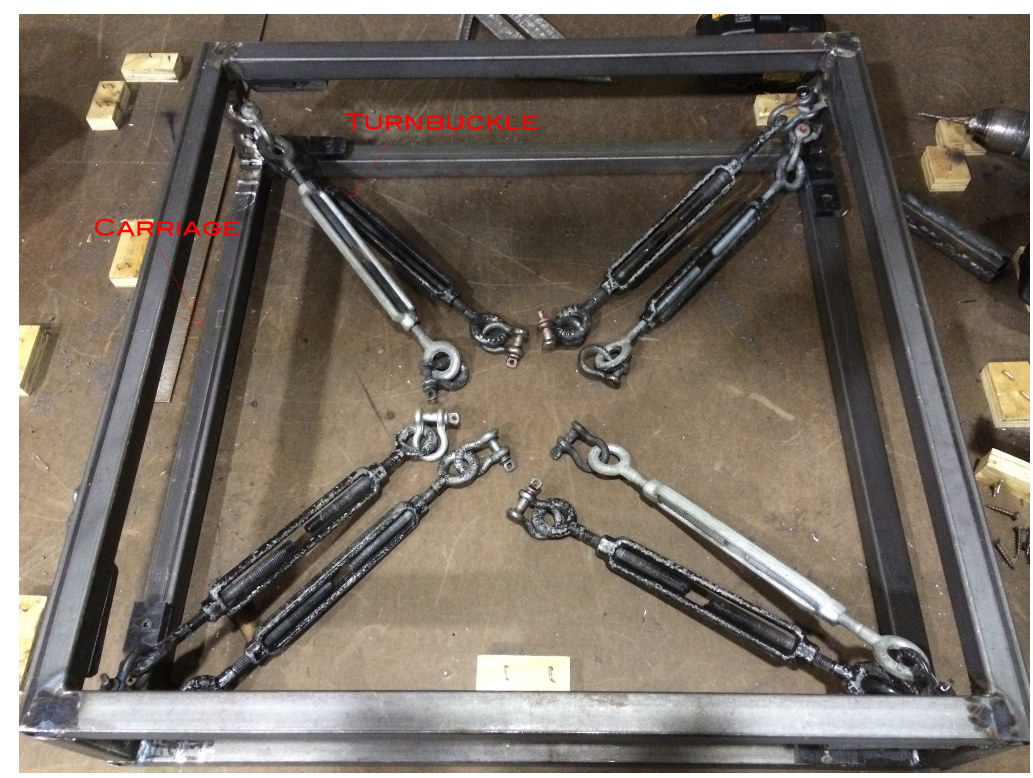

Figure 7. Turnbuckles Attached to the corners or the carriage

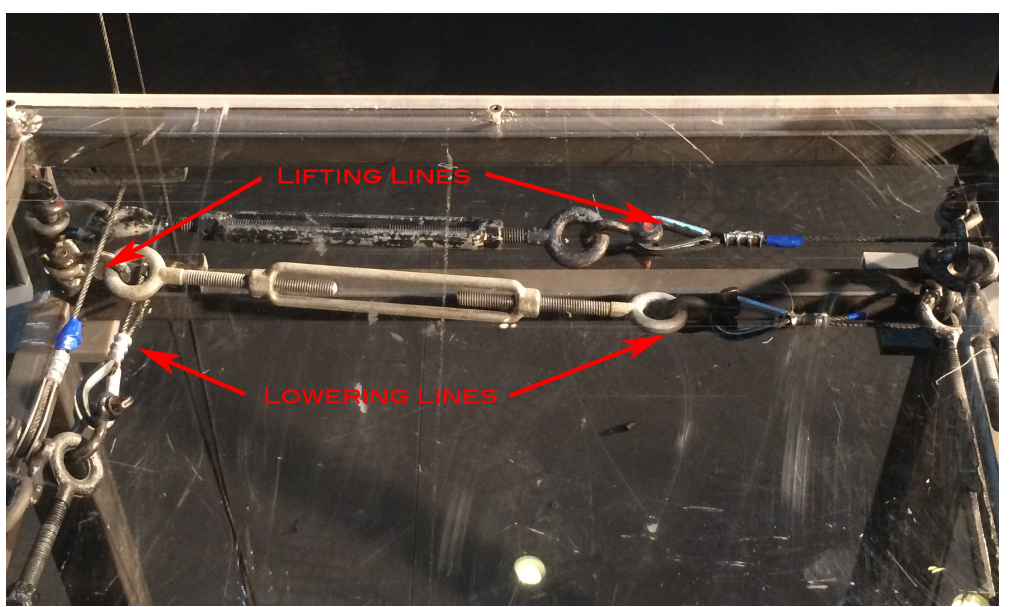

Figure 8. Turnbuckles Attached to End of Cables for Leveling 
A mule block system was built at the bottom of the tower that combines all of the cables to ensure the correct fleet angle to feed the cables straight into the drum (Figures 9,10,11). The placement of each mule block was determined by the fleet angles coming out of the head blocks. The mule blocks were spread out enough to prevent the cables from running into each other.

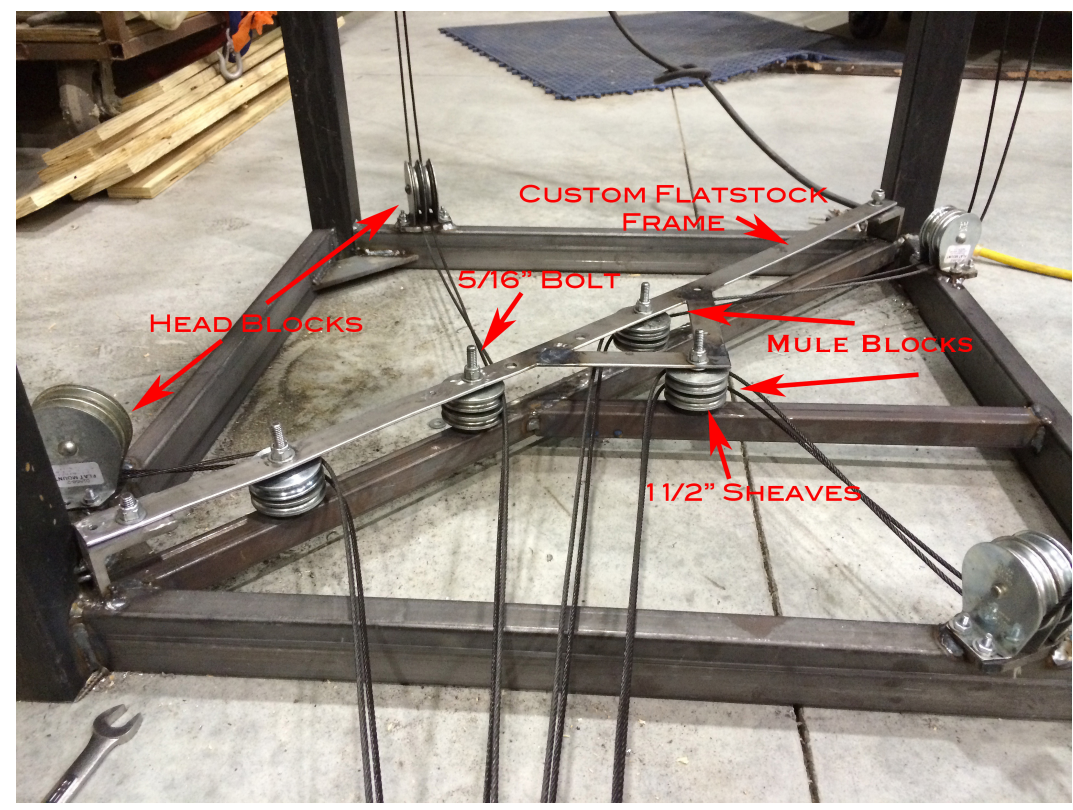

Figure 9. The mule block system at the bottom of the tower assures that the fleet angle of the cables will stay the same and will enter the winch drum at a straight angle

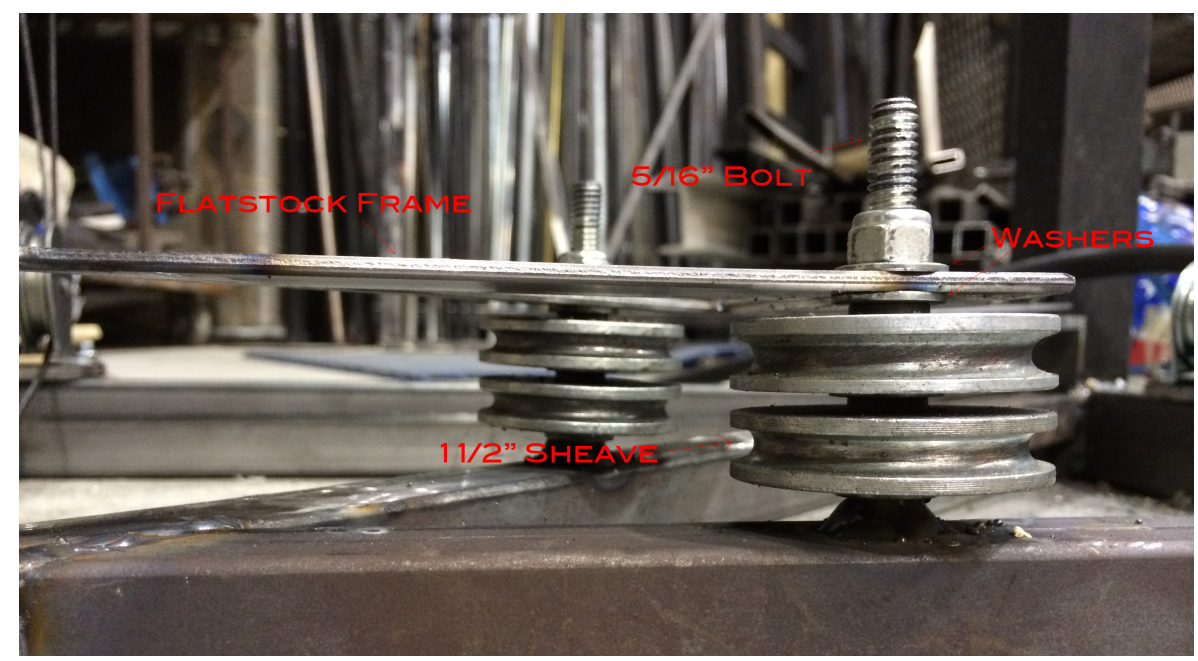

Figure 10. An up close look at the mule block system underneath the tower. This is a $5 / 16$ " bolt welded to the steel frame with a washer, sheave, washer, sheave washer stacked on it. It is then bolted to a custom made $1 / 4$ " steel flatstock bar that will prevent the bolt from bending while in tension. 


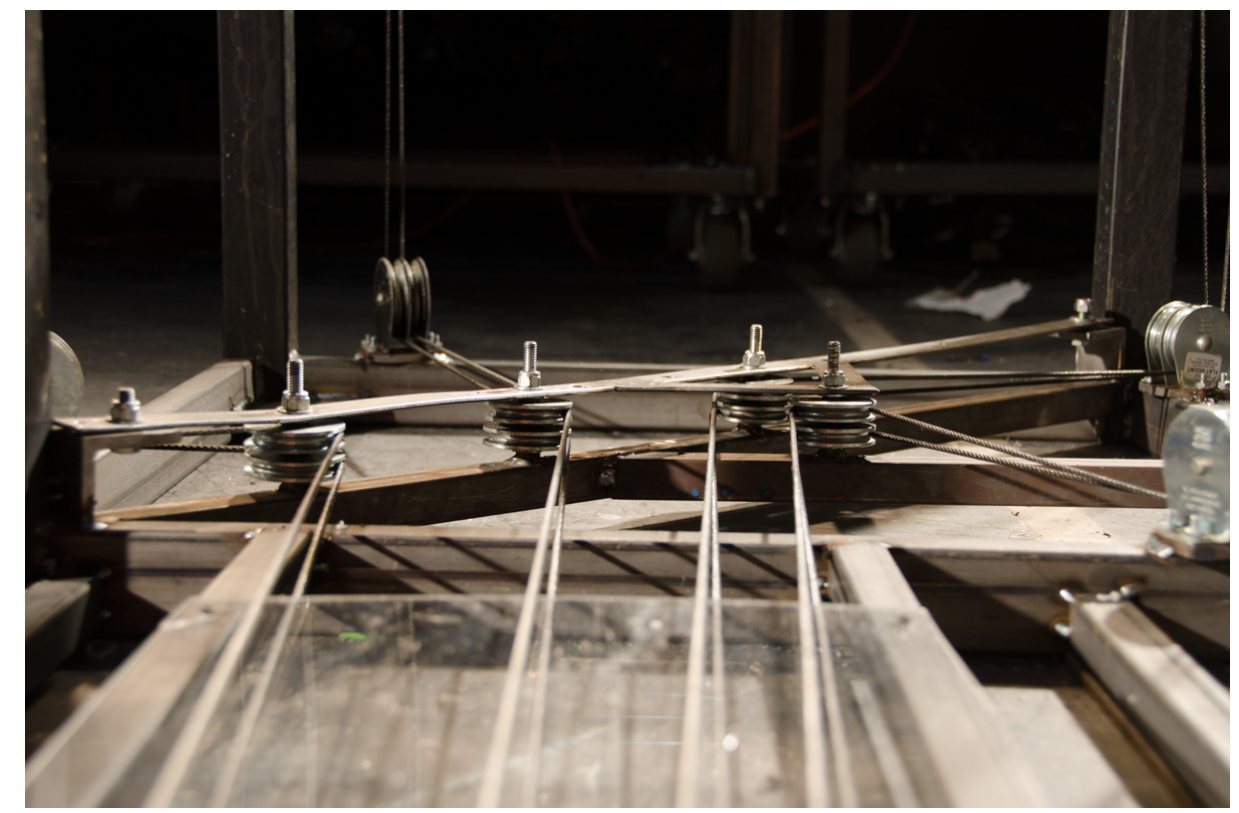

Figure 11. Fleet Angles the feed straight into the drum

The biggest problem was creating a mule block system at the bottom of the tower that worked. The most difficult part was ensuring each cable was at the perfect fleet angle heading into the winch drum. This was accomplished through some trail and error after the first two times failed to successfully attain both perfect fleet angles as well as enough clearance for the cables to run freely. The bottom sheave system was built out of a box steel frame with $5 / 16$ " bolts welded to the frame. Two $1 \frac{1 / 2}{2}$ sheaves were then placed on the bolts with washers in between to prevent rubbing and friction. The top of the sheaves included a custom-made $1 / 8$ " steel flatstock frame attached to the $5 / 16$ " bolts to prevent them from bending or breaking under tension. The end result created a precise fleet angle that guides the cables straight into the drum while the clews travel to and from the elevator. 
Once the cables were run and attached to the drum the carriage was leveled by using turnbuckles on each of the lines. Upper and lower limit switches were then added to the system to prevent the carriage from running into its own rigging (Figure 12).

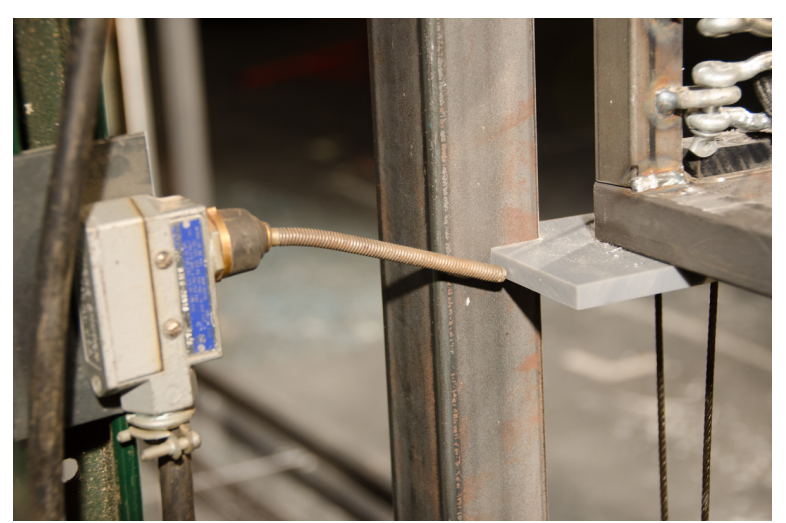

Figure 12. Limit Micro Switch

An 8 cable stage elevator system creates a easy, safe and reliable stage effect that most shops can make. Building it as a stock unit will give a theatre a stock elevator to use for any show. Building the tower in a jig will guarantee your tower is square and your rails will be level. Having the rigging self-contained in the tower unit will create an easily moveable complete unit to move under any trap opening. Using both lifting and lowering lines with create a safer and more reliable effect than just using lifting cables. The 8 cable system is a complete and great system for a stage elevator effect for any size theatre or shop. 


\section{Cabling in Drum}

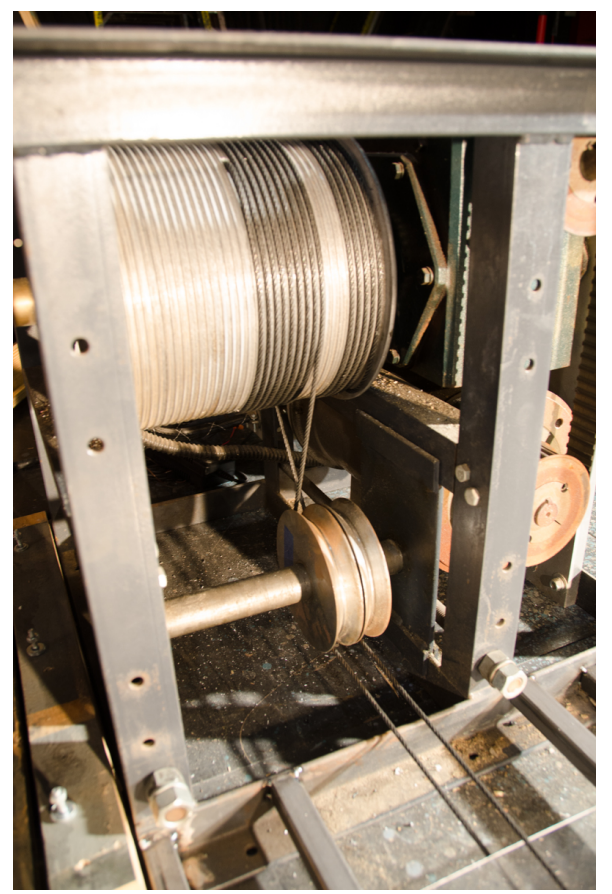

Figure 13. The two cables that feed into the drum. The cables are wrapped in opposite directions so when the drum turns one cable is being pulled into the drum and the other is going out towards the elevator.

The cable is wrapped around the drum at least 3 full times around at the cable's fullest payout to make sure it does not slip.

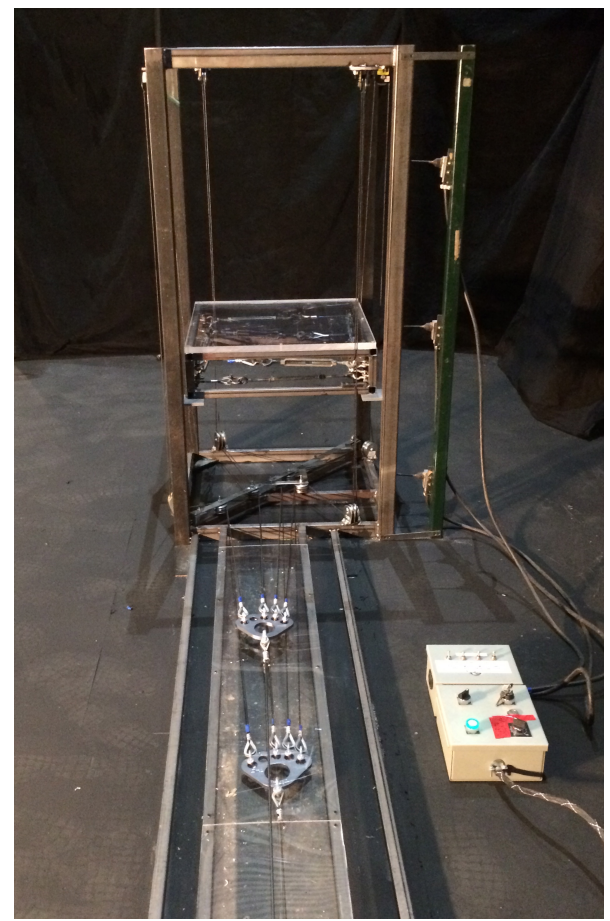

Figure 14. View from the drum of the elevator and clews 


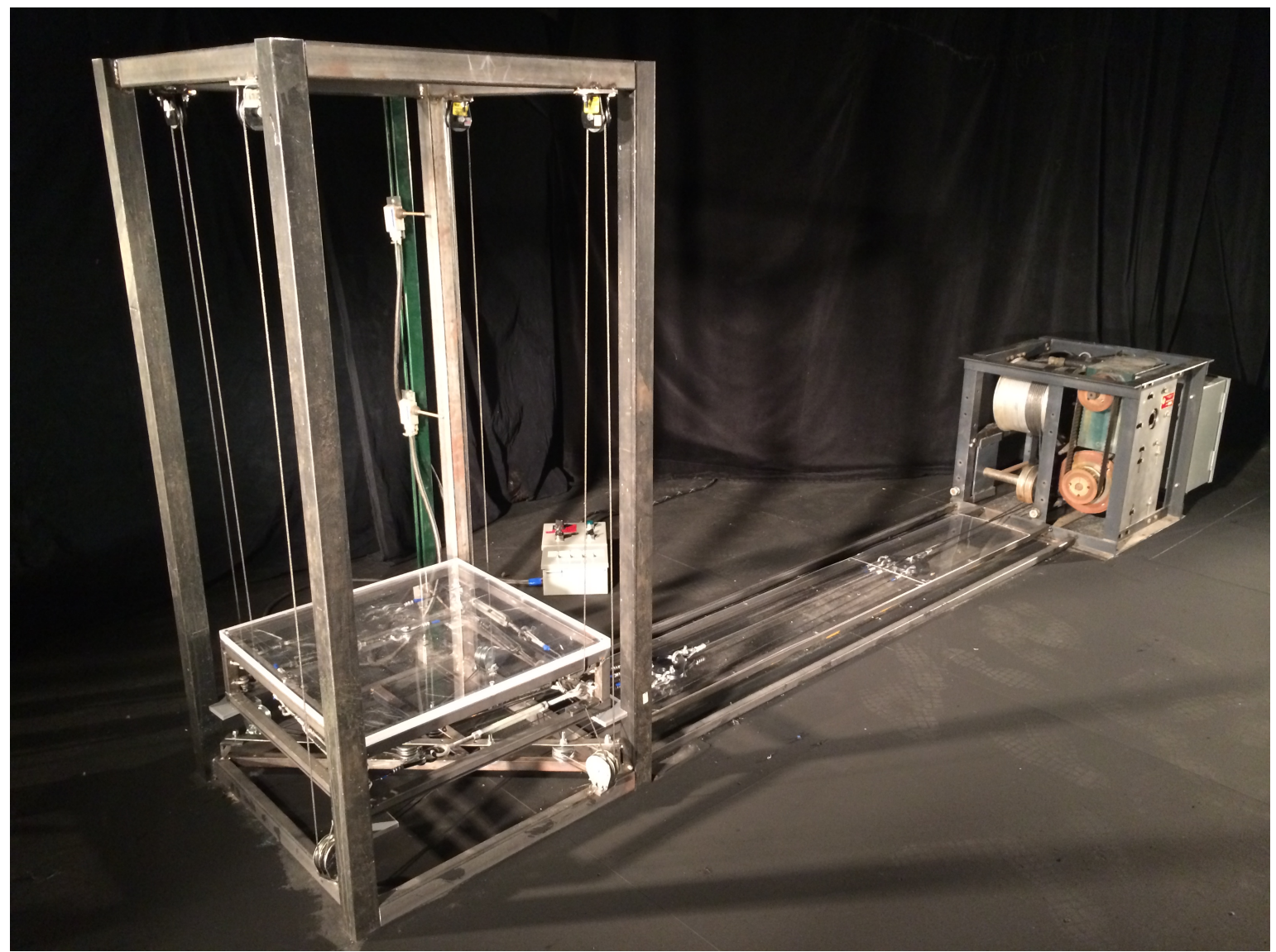

Figure 15. Finished 8-cable system elevator

Links to videos of elevator running:

https:/www.youtube.com/watch?v=ywfAVdDZ7XY

https://www.youtube.com/watch?v=vDrUmyiLnMU 